УДК 504.53 .052

DOI 10.18413/2712-7443-2020-44-1-5-15

\title{
Математическое моделирование факторов эрозии почв на пахотных землях (на примере территории Республики Татарстан)
}

\author{
А.О. Аввакумова \\ Казанский (Приволжский) федеральный университет, \\ Россия, 420008, Республика Татарстан, г. Казань, ул. Кремлевская, д. 18 \\ E-mail: avvakumova_alina@mail.ru
}

\begin{abstract}
Аннотация. На современном этапе активизации хозяйственной деятельности человека в условиях возрастающей антропогенной нагрузки на почвы изучение процесса почвенной эрозии и факторов, его обуславливающих, представляет особую значимость. Автором рассмотрены математические модели почвенной эрозии и ее развития, разработанные с целью подробного анализа вклада основных факторов эрозии с использованием данных крупномасштабных почвенных и топографических карт. По результатам исследования выделено наиболее распространенное сочетание тех условий, которые способствуют развитию эрозионных процессов на интенсивно распахиваемых землях в пределах изученной территории (Республика Татарстан). Было установлено, что вероятность проявления эрозии почв, а также увеличения ее интенсивности обусловлены прежде всего ростом величин следующих показателей: уклон, частные водосборные площади, а также ряда производных индексов (индекс конвергенции-дивергенции потока, профильная кривизна и эрозионный потенциал рельефа).
\end{abstract}

Ключевые слова: эрозия почв, почвенная карта, показатель рельефа, тип почвы, обобщенная линейная модель, Республика Татарстан.

Для цитирования: Аввакумова А.О. 2020. Математическое моделирование факторов эрозии почв на пахотных землях (на примере территории Республики Татарстан). Региональные геосистемы, 44(1): 5-15. DOI: 10.18413/2712-7443-2020-44-1-5-15

\section{Mathematical modeling of soil erosion factors on agricultural lands (on the territory of the Republic of Tatarstan)}

\author{
Alina O. Avvakumova \\ Kazan (Volga region) Federal University \\ 18 Kremlyovskaya St, Kazan, Tatarstan, 420008, Russia \\ E-mail: avvakumova_alina@mail.ru
}

\begin{abstract}
The study of the soil erosion process and its determining factors is of particular importance nowadays, in conditions of an increasing anthropogenic pressure. The article describes mathematical models of soil erosion and its development, created with the aim of a detailed analysis of the main soil erosion factors contribution (topography, soil types and particle size distribution) using large-scale soil and topographic maps. The main feature of the suggested models is that they are based on qualitative data (soil erosion categories determined by large-scale soil maps). The modeling areas of agricultural lands were determined by remote sensing data. The analysis of the models coefficients allowed to single out the most common combination of conditions conducive to the development of soil erosion processes on agricultural land within the study area (The Republic of Tatarstan). The study in prospect gives an opportunity to contain zoning of the territory according to the probability of erosion processes development. It was found that the probability of soil erosion, as well as its intensification, increases with the following indicators: slope, specific catchment area, as well as a number of derived indices (convergence-divergence flow index, profile curvature and LS-factor).
\end{abstract}


Keywords: soil erosion, soil map, topography, soil type, Generalized Linear Model, The Republic of Tatarstan.

For citation: Avvakumova, A.O. 2020. Mathematical modeling of soil erosion factors on agricultural lands (on the territory of the Republic of Tatarstan). Regional Geosystems, 44(1): 5-15. DOI: 10.18413/2712 $-7443-2020-44-1-5-15$

\section{Введение}

Почвенный покров имеет огромное значение в глобальных процессах трансформации и миграции вещества. В нем сосредоточена преобладающая масса живого вещества Земли. Почва является регулятором химического состава атмосферы и гидросферы вследствие миграции химических элементов с поверхностным стоком и испарения, является аккумулятором органического вещества и химической энергии в виде гумуса, а также огромного количества химических соединений, в том числе загрязнителей.

Почвенная эрозия - сложный, многофакторный процесс с двумя равнозначными составляющими: природной и антропогенной [Литвин, 2002]. Распашка огромных территорий, использование различных приемов мелиорации, строительство ирригационных систем и прочие виды человеческой деятельности могут серьезно нарушать сложившиеся биосферные равновесия [Дедков, Мозжерин, 1984; Morgan, 1996; Литвин, 2002; Голосов, 2006].

Значительная доля пахотных угодий приурочена к склонам той или иной крутизны, в таких условиях активная хозяйственная деятельность стимулирует развитие эрозионных процессов. При этом рельеф во многом определяет размещение новых ареалов земледельческой эрозии, также как в период освоения он во многом обуславливал закономерности размещения пашни (особенно в лесной и лесостепных зонах) [Буряк, Терехин, 2015; Ермолаев, 2017; Пространственно-временные закономерности..., 2019].

Интенсивное использование природных ресурсов, в частности почвенного покрова, во все времена сопровождалось их картографированием. Эффективное и рациональное использование земель предусматривает необходимость наличия максимально точного и полного наглядного представления информации. Эта задача успешно решается методами тематического картографирования [Лисецкий и др., 2012]. Крупномасштабное картографирование почвенного покрова производится в России согласно единой общесоюзной методике, принятой еще в 1973 г. Такой универсальный подход к составлению почвенных карт открывает широкие возможности для использования данных почвенной съемки прошлых лет и современных данных корректировки почвенных карт.

За многолетнюю историю развития эрозиоведения были разработаны и внедрены многочисленные методы оценки, моделирования и прогнозирования развития почвенной эрозии. Сложность и трудоемкость экспериментального и полевого определения интенсивности смыва вызвали повышенный интерес к математическому моделированию поверхностной эрозии [Фокин, 1986]. Развитие средств автоматизации и применение новейших инструментальных методик, таких как использование снимков беспилотных летательных аппаратов, методов наземного лазерного сканирования, позволяют с высокой точностью определять темпы плоскостного смыва и линейной эрозии [Ермолаев и др., 2018, 2019; Пространственно-временные закономерности ..., 2019]. В исследованиях динамики почвенной эрозии широко используются сочетания методов анализа данных дистанционного зондирования Земли с расчетами потерь почвы по различным видам универсальных уравнений потенциального смыва почв (USLE, RUSLE), а также с широким спектром возможностей современных ГИС-технологий [Лисецкий и др., 2012; Bosco et al., 2015; Maltsev et al., 2015; Panagos et al., 2015; Schmidt et al., 2018; Мальцев, Ермолаев, 2019]. Однако такие методы требуют выполнения достаточно строгих условий для их ис- 
пользования, большого количества специфических расчетных входных данных и не подходят для оценки развития почвенной эрозии на локальных распахиваемых территориях.

Применение классических или современных математических моделей развития почвенной эрозии в данном исследовании представлялось затруднительным, так как информация о почвенной эрозии представлена не количественными (величины поверхностного смыва почв в т/га·год), а качественными данными (категориями смытости, определенными по крупномасштабным почвенным картам). Определенные трудности связаны также со слабо развитой системой метеостанций на исследуемой территории, что не позволяет получить достаточное количество метеорологических данных для расчетов по крупномасштабным картам.

В связи с этим была поставлена задача разработать математическую модель развития почвенной эрозии, которая позволила бы оценить роль рельефа и основных характеристик почв в динамике почвенной эрозии, выделить наиболее распространенное сочетание условий, способствующих развитию эрозионных процессов на интенсивно распахиваемых землях в пределах исследуемой территории.

\section{Объекты и методы исследования}

Регион исследования (Республика Татарстан), находящийся в подзоне смешанных и широколиственных лесов и лесостепных ландшафтах востока Русской равнины, характеризуется крайне высокой интенсивностью процессов склоновой (почвенной и овражной) эрозии. Земли сельскохозяйственного назначения занимают порядка 67 \% территории республики [О состоянии природных ресурсов..., 2018]. При этом в структуре земель данного типа использования преобладает пашня (порядка 51 \% площади земель сельскохозяйственного назначения). На территории республики распространены наиболее типичные для пахотных земель европейской части России подтипы почв: дерново-подзолистые, дерново-карбонатные, серые лесные, черноземы выщелоченные и оподзоленные.

Интенсивная сельскохозяйственная освоенность территории, преимущественно тяжелый механический состав почв, низкий показатель лесистости территории создают достаточно благоприятные условия для активного развития процессов почвенной эрозии. На исследуемой территории в ходе проведенных ранее исследований были выбраны ключевые участки, характеризующие основные ландшафтные особенности территории Республики Татарстан [Аввакумова, Ермолаев, 2011; Yermolaev, Avvakumova, 2012, 2014] (рис. 1).

В качестве исходных материалов использовались крупномасштабные карты почвенных обследований прошлых лет и карты почвенных корректировок масштаба 1:10 000, предоставленные ОАО РКЦ «Земля». Почвенные карты, ранее сделанные на бумажной основе в Волго-Вятском филиале Гипрозема (почвенные обследования 1967-1985 гг.), были отсканированы и оцифрованы средствами программы EasyTrace 7.99 Pro. Координатная привязка проводилась вручную по произвольному набору точек (по границам каждого ключевого участка). Погрешность составила не более 5 м. На основе оцифрованных карт были составлены карты почвенной эрозии. Электронные карты почвенных корректировок (почвенные обследования 2001-2005 гг.), предоставленные ОАО РКЦ «Земля», были импортированы из ГИС «Панорама» в ГИС MapInfo.

Поскольку интенсивное развитие почвенной эрозии продолжается на распахиваемых участках, области моделирования были ограничены землями пашни, границы которой были определены по результатам дешифрирования данных дистанционного зондирования Земли. В исследовании использовались разновременные снимки, полученные со спутников Landsat 5 и Landsat 8 [Landsat - Earth observation satellites, 2015]. Данные были получены из свободного ресурса - архива геологической службы США USGS United States Geological Survey (www.earthexplorer.usgs.gov). 


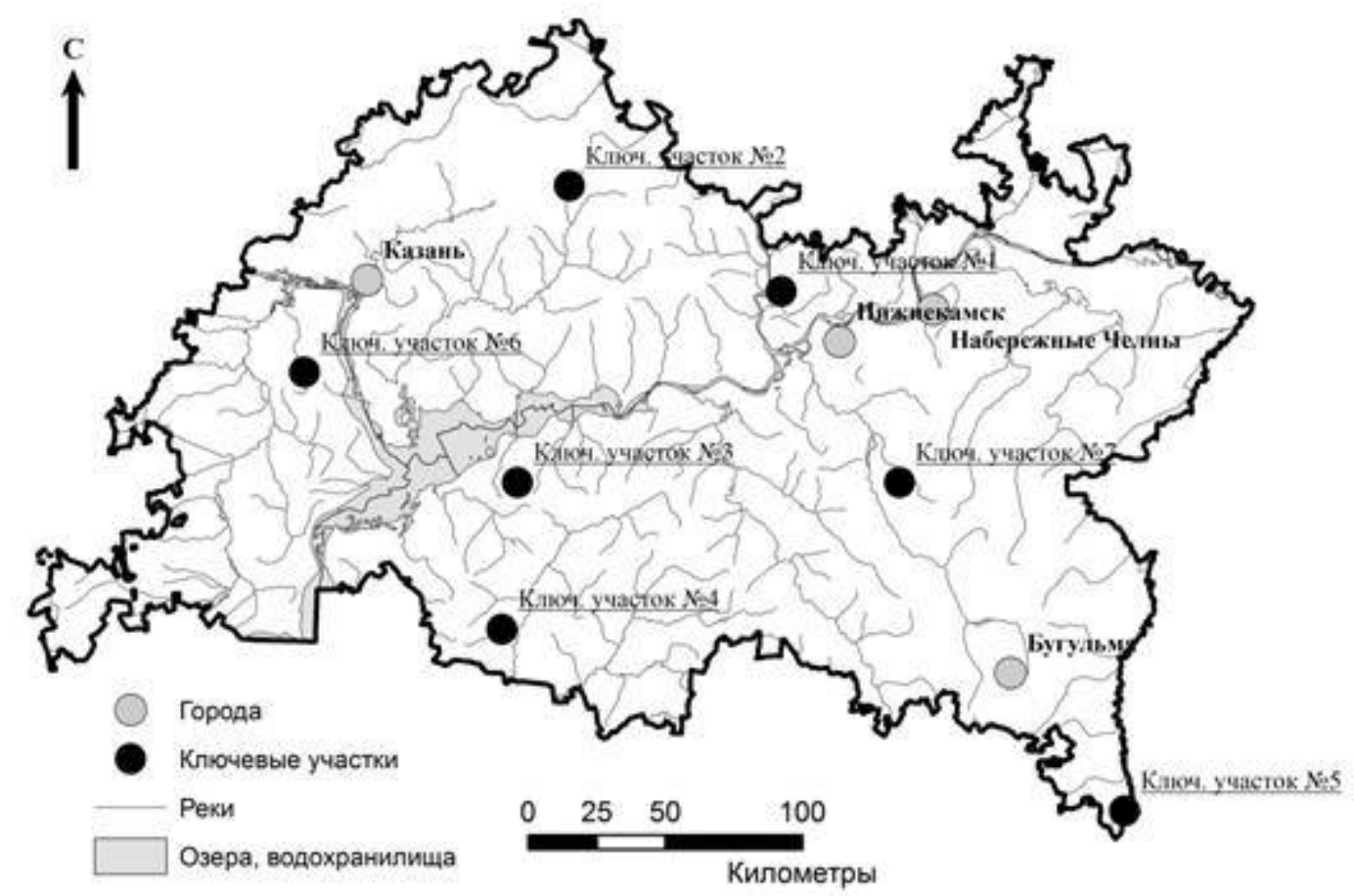

Рис. 1. Расположение ключевых участков на исследуемой территории

Fig. 1. Location of key sites in the study area

В качестве информации об эрозии (зависимая переменная модели) использовались контура эрозии. На почвенной карте степень эрозии относится к почвенному контуру в целом и представлена тремя градациями: 0 - несмытые почвы; 1 - слабосмытые почвы; 2 - среднесмытые почвы.

В качестве независимых переменных в модели были использованы значения типов почв, гранулометрического состава, а также индексы рельефа:

topo - отметки высот рельефа (в метрах);

slope - угол наклона поверхности;

curv_plan - плановая кривизна;

curv_prof - профильная кривизна;

up_leng - средняя длина линий тока;

Rho8_sca - частная водосборная площадь, построенная по алгоритму Rho8;

upslope - частная водосборная площадь, построенная по алгоритму MDInf;

$L S$ - эрозионный потенциал рельефа;

con_div_index - индекс конвергенции-дивергенции потока;

stream_power - индекс мощности потока;

WetInd - индекс увлажненности.

Для расчета индексов рельефа использовалась цифровая модель, построенная путем интерполяции из изолинейных топографических карт масштаба 1:25 000. Цифровая модель рельефа (ЦМР) представлена в виде растровой сетки (геоинформационного слоя) с размером ячеек 10×10 метров. Листы топокарт в формате .sxf были предоставлены ФГУП «Средневолжское АГП». Для генерирования ЦМР используется модуль $3 D$ Analyst Tools, оператор Topo to raster. В пределах каждого ключевого участка по полученным ЦМР средствами ГИС Whitebox и Surfer были рассчитаны перечисленные выше индексы рельефа. 
Использование широкого набора производных морфометрических индексов рельефа при моделировании может приводить к возникновению ошибок вследствие их возможной корреляции между собой. В связи с этим были вычислены парные коэффициенты корреляции между показателями, затем наиболее значимые (выбранные на основе анализа вкладов отдельных предикторов), но при этом наименее скоррелированные между собой индексы были объединены в два набора. После этого была проведена проверка наборов на наличие мультиколлинеарности, т. е. наличие линейной зависимости между несколькими переменными.

В исследовании использовались инструменты статистической обработки и математического моделирования в свободной программной среде $\mathrm{R}$ (http: //www.rproject.org/) [R Core Team, 2014].

После проведенных исследований наборы переменных приняли следующий вид:

Набор 1: уклон, индекс мощности потока, профильная кривизна, частная водосборная площадь, отметки высот рельефа, индекс конвергенции-дивергенции потока, типы почв, гранулометрический состав.

Набор 2: эрозионный потенциал рельефа (LS - фактор), индекс увлажненности, профильная кривизна, частная водосборная площадь, отметки высот рельефа, индекс конвергенции-дивергенции потока, типы почв, гранулометрический состав.

Поскольку значение эрозии представлено дискретной переменной, имеющей только три значения, для решения задачи было решено построить несколько биномиальных моделей, использующих значения зависимой переменной Истина/Ложь или 1/0.

Были построены следующие модели:

1) модель наличия почвенной эрозии, независимо от ее степени (степень эродированности >0) (Model 1);

2) модель отличия почвенной эрозии степени 2 (среднесмытые почвы) от степени 1 (слабо смытые почвы) (Model 2);

3) модель увеличения степени «новой» эрозии по сравнению со «старой» (Model 3).

В качестве инструмента для моделирования используется обобщенная линейная модель (GLM - Generalized Linear Model). Это универсальный метод построения регрессионных моделей, позволяющий учитывать взаимодействие между факторами, вид распределения зависимой переменной и предположения о характере регрессионной зависимости.

Вероятность соответствующего случая (например, наличия эрозии для Модели (1) при использовании логистической функции принимает следующий вид:

$$
\begin{gathered}
P\left(Y_{i}\right)=\frac{1}{1+e^{-\mu_{i}}}, \\
\mu_{i}=a_{0}+a_{\text {region }}+a_{\text {newerosion }}+b_{1} x_{i, 1}+b_{2} x_{i, 2}+\cdots+b_{n} x_{i, n},
\end{gathered}
$$

где $P\left(Y_{i}\right)$ - вероятность соответствующего случая в $i$-й точке, $\mu_{i}-$ линейный предиктор, $a_{0}-$ константа модели, $a_{\text {region }}$ - поправка к константе модели для конкретного участка (района), $a_{\text {newerosion }}$ поправка к константе модели для случая, когда используется новые значения смытости; $b_{1}, b_{2}, \ldots b_{n}$ - коэффициенты модели, и $x_{i, 1}, x_{i, 2}, \ldots x_{i, n}-$ значения переменных в $i$-й точке.

\section{Результаты и их обсуждение}

Анализ значений коэффициентов детерминации $\mathrm{R}^{2}$ (доля дисперсии результативного признака, которая объясняется влиянием независимых переменных) для наиболее зна- 
чимых переменных (табл. 1, 2) показал, что переменные потоков сделались незначимыми или слабо значимыми. Этот факт объясняется тем, что область моделирования была ограничена пахотными землями, на которых уклоны поверхности минимальны, в связи с этим скорости образующихся склоновых потоков незначительны. Таким образом, первая группа переменных несколько лучше описывает независимую переменную (степень почвенной эрозии), поэтому в обсуждении результатов ограничимся анализом оценок коэффициентов моделей, построенных с использованием первого набора переменных.

Таблица 1

Table 1

Значения коэффициентов детерминации $\mathrm{R}^{2}$

для наиболее значимых переменных (1 набор переменных)

The values of the $\mathrm{R}^{2}$ for the most significant variables (the $1^{\text {st }}$ set of variables)

\begin{tabular}{|l|c|c|c|}
\hline \multirow{2}{*}{\multicolumn{2}{|c|}{ Независимые переменные (индексы рельефа) }} & \multicolumn{3}{|c|}{ Коэффициент детерминации, \% } \\
\cline { 2 - 4 } & Model 1 & Model 2 & Model 3 \\
\hline Уклон рельефа & 11,907 & 9,16 & 5,187 \\
\hline Индекс мощности потока & 2,43 & 1,365 & 1,257 \\
\hline Профильная кривизна & 0,295 & 0,339 & 0,264 \\
\hline Частная водосборная площадь & 0,554 & 0,102 & 0,473 \\
\hline Отметки высот рельефа (в метрах) & 0,16 & 0,014 & 0,209 \\
\hline Индекс конвергенции-дивергенции потока & 0,014 & 0,04 & 0,052 \\
\hline
\end{tabular}

Значения коэффициентов детерминации $\mathrm{R}^{2}$

для наиболее значимых переменных (2 набор переменных)

The values of the $\mathrm{R}^{2}$ for the most significant variables (the $2^{\text {nd }}$ set of variables)

\begin{tabular}{|l|c|c|c|}
\hline \multirow{2}{*}{\multicolumn{2}{|c|}{ Независимые переменные (индексы рельефа) }} & \multicolumn{3}{|c|}{ Коэффициент детерминации, \% } \\
\cline { 2 - 4 } & Model 1 & Model 2 & Model 3 \\
\hline Эрозионный потенциал рельефа (LS - фактор) & 8,169 & 5,623 & 3,865 \\
\hline Индекс увлажненности & 1,182 & 0,819 & 0,412 \\
\hline Профильная кривизна & 0,295 & 0,339 & 0,264 \\
\hline Частная водосборная площадь & 0,554 & 0,102 & 0,473 \\
\hline Отметки высот рельефа (в метрах) & 0,16 & 0,014 & 0,209 \\
\hline Индекс конвергенции-дивергенции потока & 0,014 & 0,04 & 0,052 \\
\hline
\end{tabular}

Для примера в табл. 3 приведены оценки некоторых коэффициентов построенной нами модели (модель 1 с первым набором переменных). 
Значения некоторых коэффициентов модели 1 с первым набором переменных Model 1 coefficients (with the use of the $1^{\text {st }}$ set of variables)

\begin{tabular}{|c|c|c|}
\hline Переменная модели & $\begin{array}{c}\text { Коэффициент } \\
\text { модели }\end{array}$ & $\begin{array}{c}\text { Наблюдаемый } \\
\text { уровень } \\
\text { значимости }\end{array}$ \\
\hline (Intercept) & $-1,90$ & $<0,001$ \\
\hline fRegionAlkeev & 0,41 & $<0,001$ \\
\hline fRegionBavly & $-5,63$ & $<0,001$ \\
\hline fRegionElab & $-2,15$ & $<0,001$ \\
\hline fRegionSabinsk & 0,21 & $<0,001$ \\
\hline fRegionVerhneusl & 1,34 & $<0,001$ \\
\hline NewErosionTRUE & 0,79 & $<0,001$ \\
\hline Уклон & 4,21 & $<0,001$ \\
\hline Индекс мощности потока & $-0,004$ & 0,084 \\
\hline Профильная кривизна & 0,15 & $<0,001$ \\
\hline Частная водосборная площадь & 0,26 & $<0,001$ \\
\hline Отметки высот рельефа & $-0,0008$ & $<0,001$ \\
\hline Индекс конвергенции-дивергенции потока & 0,02 & $<0,001$ \\
\hline Коричнево-серая лесная оподзоленная & 4,45 & $<0,001$ \\
\hline Светло-серая лесная & 1,78 & $<0,001$ \\
\hline Серая лесная оподзоленная & 1,92 & $<0,001$ \\
\hline Чернозем карбонатный маломощный & 5,10 & $<0,001$ \\
\hline Чернозем карбонатный среднемощный & 4,51 & $<0,001$ \\
\hline \multicolumn{3}{|c|}{ Гранулометрический состав: } \\
\hline - среднесуглинистый & 0,23 & $<0,001$ \\
\hline - легкосуглинистый & $-0,08$ & $<0,001$ \\
\hline - супесчаный & $-0,17$ & $<0,001$ \\
\hline
\end{tabular}

В первой строке второго столбца мы видим информацию, относящуюся к коэффициенту $a_{0}$ уравнения модели (2). В последующих строках этого столбца представлены остальные коэффициенты модели. Они показывают направление изменения вероятности: если знак положительный, то вероятность растет с ростом соответствующей переменной, если отрицательный - падает. Последний столбец показывает значимость переменных: если величина менее 0,05 , то переменная считается значимой. 
Первая модель (модель, по которой рассчитывали вероятность наличия почвенной эрозии независимо от ее степени) с использованием первого набора переменных показала, что вероятность наличия почвенной эрозии прямо пропорциональна уклону, частным водосборным площадям, индексу конвергенции-дивергенции потока и профильной кривизне (см. табл. 3).

Обратная зависимость выявляется с индексом мощности потока (который в этой модели сделался незначимым) и отметками высот рельефа. Такие зависимости легко объясняются физическим значением этих переменных. Как известно, профильная кривизна напрямую связана с замедлением и ускорением потока по склону. Чем больше значение профильной кривизны, тем более вогнутой является поверхность. Участки с большими уклонами и выпуклым профилем склона, как правило, не распахиваются. Поскольку область моделирования ограничена пахотными землями, в данном случае наблюдается прямая зависимость вероятности наличия почвенной эрозии со значениями профильной кривизны. Обратная зависимость в случае с отметками высот также может быть объяснена спецификой размещения распахиваемых участков. Участки с наибольшей высотой располагаются на водоразделах. Эти уплощенные области имеют минимальные уклоны и меньше подвержены эрозии, нежели склоновые части, расположенные ниже.

Наиболее значимые типы почв одновременно являются и самыми распространенными на ключевых участках. Из представленных типов почв в наибольшей степени вероятность наличия почвенной эрозии связана с черноземами карбонатными маломощными и среднемощными. Эти подтипы имеют самую низкую противоэрозионную стойкость в ряду черноземов [Заславский, 1983].

Вероятность наличия смытых почв на среднесуглинистых почвах выше, чем на легкосуглинистых и супесчаных. По-видимому, это связано с более широким распространением почв такого гранулометрического состава на исследуемых участках.

Модель 2 описывает отличие почвенной эрозии степени 2 от степени 1. Другими словами, модель считает, какова вероятность того, что смытая почва в конкретной точке будет иметь категорию среднесмытой. В этом случае со всеми показателями рельефа из 1 набора данных наблюдается прямая зависимость с вероятностью возникновения среднесмытых почв. При этом переменная мощности потока сделалась незначимой. Таким образом, можно сказать, что вероятность возникновения среднесмытых почв наибольшая на верхних участках склонов вогнутого профиля. При этом наиболее сильная зависимость наблюдается именно в отношении уклонов. Анализируя оценки коэффициентов модели, можно сказать, что среднесмытые почвы с наибольшей вероятностью локализованы на коричнево-серых лесных оподзоленных, дерново-карбонатных, серых лесных оподзоленных почвах, расположенных в верхней части склонов и имеющих среднесуглинистый гранулометрический состав.

Интересные результаты показали коэффициенты третьей модели (модель увеличения степени «новой» эрозии по сравнению со «старой»). В данном случае вычисляется вероятность того, что в каждой точке степень эродированности с карты почвенной корректировки будет больше, чем на исходной почвенной карте.

Вероятность увеличения степени эродированности имеет прямую корреляцию с уклонами, частными водосборными площадями, индексом конвергенции-дивергенции потока, профильной кривизной и отметками рельефа. Наибольшие значения этих показателей характеризуют верхние и средние участки склонов с вогнутым профилем.

Интересно отметить, что из всех типов почв, которые оказались значимыми для этой модели, вероятность возрастания почвенной эрозии наибольшая у черноземов карбонатных мало- и среднемощных, а также у лугово-черноземных карбонатных среднемощных. Также, по результатам моделирования, наибольшая вероятность увеличения показателя смытости - у супесчаных почв. 


\section{Заключение}

Представленное исследование базируется на обширном исходном материале, включающем в себя крупномасштабные почвенные и топографические карты, данные дистанционного зондирования Земли. Были разработаны региональные математические модели развития почвенной эрозии, в которых эродированность почв представлена качественной характеристикой (категорией смытости), что позволяет использовать большой объем данных, представленных на разновременных крупномасштабных почвенных картах.

В ходе исследования математико-статистическими методами был оценен вклад каждого из рассчитанных показателей рельефа (уклон, плановая и профильная кривизна, экспозиция, средняя длина линий тока, удельная площадь водосбора (specific catchment area), эрозионный потенциал рельефа (LS-factor), индекс увлажненности (Wetness index), индекс мощности потока (Relative stream power index).

Вероятность наличия почвенной эрозии, а также ее увеличения прогрессирует с ростом следующих показателей рельефа: уклона, частных водосборных площадей, индексом конвергенции-дивергенции потока, профильной кривизной и эрозионным потенциалом рельефа. Отметки высот обратно пропорциональны росту вероятности наличия почвенной эрозии, однако прямо пропорциональны вероятности увеличения категории смытости.

Следовательно, образование и развитие почвенной эрозии на ключевых участках идет в основном в верхних частях склонов с вогнутым профилем. Наличие почвенной эрозии, а также ее рост наиболее вероятны на среднесуглинистых почвах, относящихся к черноземам карбонатным маломощным и среднемощным. Однако наличие почв средней степени смытости в большей степени вероятно на дерново-карбонатных, коричнево-серых оподзоленных, светло-серых, серых лесные почвах.

Перспективу дальнейших исследований мы связываем с разработкой схем районирования территории по вероятности развития эрозионных процессов для определения ожидаемых тенденций развития эрозии почв.

Автор выражает глубокую благодарность научному руководителю, доктору географических наук, профессору Ермолаеву О.П., сотрудникам кафедр ландмафтной экологии и моделирования экологических систем, в частности, профессору Савельеву А.А.

\section{Список использованных источников}

1. Об утверждении требований к государственным топографическим картам и государственным топографическим планам, включая требования к составу сведений, отображаемых на них, к условным обозначениям указанных сведений, требования к точности государственных топографических карт и государственных топографических планов, к формату их представления в электронной форме, требований к содержанию топографических карт, в том числе рельефных карт: Приказ Минэкономразвития России от 06.06.2017 № 271 (ред. от 11.12.2017) // СПС КонсультантПлюс. URL: http://www.consultant.ru/ document /cons_doc LAW 219559/(дата обращения: 23 октября 2019).

2. О состоянии природных ресурсов и об охране окружающей среды Республики Татарстан в 2018 году: государственный доклад. Электронная книга. URL: http:/eco.tatarstan.ru /rus/file/pub/pub_1928270.pdf (дата обращения: 28 января 2020).

\section{Список литературы}

1. Аввакумова А.О., Ермолаев О.П. 2011. Методика оценки пространственно-временной динамики эрозии почв по материалам повторных почвенных съемок в регионе интенсивного земледелия средствами ГИС-технологий. Вестник Удмуртского университета. Серия «Биология. Науки о Земле», 4: 3-7.

2. Буряк Ж.А., Терехин Э.А. 2015. Противоэрозионное обустройство агроландшафтов на основе оценки потенциальных эрозионных потерь почвы с использованием ГИС-технологий. Науки о Земле: вчера, сегодня, завтра. Материалы международной научной конференции, Казань, Бук: 1-7. 
3. Голосов В.Н. 2006. Эрозионно-аккумулятивные процессы в речных бассейнах освоенных равнин. М., ГЕОС, 296 с. $264 \mathrm{c}$.

4. Дедков А.П., Мозжерин В.И. 1984. Эрозия и сток наносов на Земле. Казань. Изд-во КГУ,

5. Ермолаев О.П. 2017. Геоинформационное картографирование эрозии почв в регионе Среднего Поволжья. Почвоведение, 1: 130-144.

6. Ермолаев О.П., Гафуров А.М., Усманов Б.М. 2018. Оценка интенсивности и динамики эрозии методом наземного лазерного сканирования. Почвоведение, 7: 893-906.

7. Ермолаев О.П., Усманов Б.М., Гафуров А.М., Голосов В.Н. 2019. Оценка темпов смыва на склонах методом наземного лазерного сканирования. В кн.: Голосов В.Н., Ермолаев О.П. Пространственно-временные закономерности развития современных процессов природноантропогенной эрозии на Русской равнине. Казань, АН РТ: 115-122.

8. Заславский М.Н. 1983. Эрозиоведение. М., Высшая школа, 320 с.

9. Лисецкий Ф.Н., Светличный А.А., Черный С.Г. 2012. Современные проблемы эрозиоведения. Белгород, Константа. $456 \mathrm{c}$.

10. Литвин Л.Ф. 2002. География эрозии почв сельскохозяйственных земель России. М., ИКЦ Академкнига, $255 \mathrm{c}$.

11. Мальцев К.А. Ермолаев О.П. 2019. Оценка потенциальных потерь почвы на сельскохозяйственных землях Европейской части России. Закономерности проявления эрозионных и русловых процессов в различных природных условиях. Материалы $\mathrm{V}$ Всероссийской научной конференции с международным участием, объединенной с XXXIV пленарным совещанием Межвузовской научно-координационного совета по проблеме эрозионных, русловых и устьевых процессов. Москва, ЛЕНАНД: 294-296.

12. Пространственно-временные закономерности развития современных процессов природно-антропогенной эрозии на Русской равнине. 2019. Под ред. В.Н. Голосова, О.П. Ермолаева. Казань, Изд-во АН РТ, 372 с.

13. Фокин А.Д. 1986. Почва, биосфера и жизнь на Земле. М., Наука, 138 с.

14. Bosco C., de Rigo D., Dewitte O., Poesen J., Panagos P. 2015. Modelling soil erosion at European scale: towards harmonization and reproducibility. Natural Hazards and Earth System Sciences, 15 (2): 225-245.

15. Landsat - Earth observation satellites. 2015. U.S. Geological Survey. Reston, VA. 4.

16. Maltsev K.A., Yermolaev O.P., Mozzherin V.V. 2015. Suspended sediment yield mapping of Northern Eurasia. Proceedings IAHS: 326-332.

17. Morgan R.P.C. 1996. Soil Erosion and conservation. London, New York, Publ. Longman, $198 \mathrm{p}$.

18. Panagos P. 2015. A new European slope length and steepness factor (LS-Factor) for modeling soil erosion by water. Geosciences. Switzerland, 5: 117-126.

19. R Core Team. R: A language and environment for statistical computing. R Foundation for Statistical Computing. 2014. Electronic resource. Available at: http://www.R-project.org/ (accessed: 07 March 2019).

20. Schmidt S. 2018. Mapping spatio-temporal dynamics of the cover and management factor (Cfactor) for grasslands in Switzerland. Remote Sensing of Environment, 211: 89-104.

21. Yermolaev O., Avvakumova A. 2012. Cartographic-geoinformational estimation of spatiotemporal erosion dynamics of arable soils in forest-steppe landscapes of the Russian Plain. IAHS-AISH Publication, 356: 332-337.

22. Yermolaev O., Avvakumova A. 2014. GIS Methods In Evaluation Of Arable Soils' SpatialTime Erosion Dynamics On The Territory Of The Russian. 14th International Multidisciplinary Scientific Geoconference SGEM, 3: 627-633.

\section{References}

1. Avvakumova A.O., Ermolaev O.P. 2011. Methodology for estimating spatial and temporal dynamics of soil erosion from repeated soil surveys in the region of intensive agriculture using GIS technologies. Bulletin of the Udmurt university. Series "Biology. Sciences about Earth", 4: 3-7. (in Russian)

2. Burjak Zh.A., Terehin E.A. 2015. Anti-erosion management of agrolandshafts based on assessment of potential soil erosion losses using GIS technologies. Earth sciences: yesterday, today, tomorrow. Proceedings of the International Scientific Conference. Kazan, Buk: 1-7. (in Russian) 
3. Golosov V.N. 2006. Транслит названия. [Erosion-storage processes in river basins of developed plains]. Moscow, Publ. GEOS, 296 p. (in Russian)

4. Dedkov A.P., Mozzherin V.I. 1984. Jerozija i stok nanosov na Zemle [Erosion and runoff of sediments on Earth]. Kazan, Publ. KGU, 264 p.

5. Ermolaev O.P. 2017. Geo-informational mapping of soil erosion in the Middle Volga region. Soil science, 1: 130-144. (in Russian)

6. Ermolaev O.P., Gafurov A.M., Usmanov B.M. 2018. Estimation of erosion intensity and dynamics by ground laser scanning. Soil science, 7: 893-906. (in Russian)

7. Ermolaev O.P., Usmanov B.M., Gafurov A.M., Golosov V.N. 2019. Транслит названия. Estimation of the rate of flush on slopes by ground laser scanning. V kn.: Golosov V.N., Ermolaev O.P. Транслит названия. Spatio-temporal patterns of contemporary processes dynamics of natural and human-induced erosion on agricultural lands of the Russian Plain. Kazan, Publ. AN RT: 115-122. (in Russian)

8. Zaslavskij M.N. 1983. Jeroziovedenie. [Erosion studies]. Moscow, Publ. High School, 320 p.

9. Liseckii F.N., Svetlichnyi A.A., Chernyi S.G. 2012. Modern problems of erosion science. Belgorod, Publ. Konstanta. 456 p. (in Russian)

10. Litvin L.F. 2002. Soil erosion geography of agricultural lands in Russia. Moscow, Publ. IKC Akademkniga, $255 \mathrm{p}$.

11. Mal'cev K.A., Ermolaev O.P. 2019. Assessment of potential soil losses on agricultural land in the European part of Russia. Patterns of erosion and channel processes in various environmental conditions. Materials of the V All-Russian Scientific Conference with international participation, combined with the XXXIV plenary meeting of the Interuniversity Scientific Coordination Council on the problem of erosion, channel and wellhead processes. Moscow, Publ. LENAND: 294-296. (in Russian)

12. Spatio-temporal patterns of contemporary processes dynamics of natural and human-induced erosion on agricultural lands of the Russian Plain. 2019. Kazan, Publ. AN RT, 372 p. (in Russian)

13. Fokin A.D. 1986. Pochva, biosfera i zhizn' na Zemle [Soil, biosphere and life on Earth]. Moscow, Publ. Science, $138 \mathrm{p}$.

14. Bosco C., de Rigo D., Dewitte O., Poesen J., Panagos P. 2015. Modelling soil erosion at European scale: towards harmonization and reproducibility. Natural Hazards and Earth System Sciences, 15 (2): $225-245$.

15. Landsat - Earth observation satellites. 2015. U.S. Geological Survey. Reston, VA. 4.

16. Maltsev K.A., Yermolaev O.P., Mozzherin V.V. 2015. Suspended sediment yield mapping of Northern Eurasia. Proceedings IAHS: 326-332.

17. Morgan R.P.C. 1996. Soil Erosion and conservation. London, New York, Publ. Longman, $198 \mathrm{p}$.

18. Panagos P. 2015. A new European slope length and steepness factor (LS-Factor) for modeling soil erosion by water. Geosciences. Switzerland, 5: 117-126.

19. R Core Team. R: A language and environment for statistical computing. R Foundation for Statistical Computing. 2014. Electronic resource. Available at: http://www.R-project.org/ (accessed: 07 March 2019).

20. Schmidt S. 2018. Mapping spatio-temporal dynamics of the cover and management factor (Cfactor) for grasslands in Switzerland. Remote Sensing of Environment, 211: 89-104.

21. Yermolaev O., Avvakumova A. 2012. Cartographic-geoinformational estimation of spatiotemporal erosion dynamics of arable soils in forest-steppe landscapes of the Russian Plain. IAHS-AISH Publication, 356: 332-337.

22. Yermolaev O., Avvakumova A. 2014. GIS Methods In Evaluation Of Arable Soils' SpatialTime Erosion Dynamics On The Territory Of The Russian. 14th International Multidisciplinary Scientific Geoconference SGEM, 3: 627-633.

\section{ИНФОРМАЦИЯ ОБ АВТОРЕ}

Аввакумова А.О., ассистент кафедры ландшафтной экологии института экологии и природопользования Казанского (Приволжского) Федерального университета, г. Казань, Россия

\section{INFORMATION ABOUT THE AUTHOR}

Alina O. Avvakumova, assistant of the Department of landscape ecology, Institute of ecology and nature management, Kazan (Volga region) Federal University, Kazan, Russia 